\title{
Employee Management System
}

\author{
Rishabh Bajpayi ${ }^{1}$ | Prof. M L Sharma ${ }^{2}$ | K C Tripathi ${ }^{3}$ \\ Department of Information Technology, Maharaja Agrasen Institute of Technology, Delhi, India.
}

To Cite this Article

Rishabh Bajpayi, Prof. M L Sharma and K C Tripathi, "Employee Management System", International Journal for Modern Trends in Science and Technology, 6(12): 225-234, 2020.

\section{Article Info}

Received on 10-November-2020, Revised on 02-December-2020, Accepted on 06-December-2020, Published on 10-December-2020.

\section{ABSTRACT}

Employee management system is an application based system, having two applications developed, one for employers to manage employee details and another for employees to mark their attendance. Every organisation whether government or private uses an information system[2.] to store data of their staff. However, in India it is found that many small scale industries use pen and paper to keep a record. However, there are many advanced technology systems available that can do this work but they all are costly for these low level industries. This paper discusses making a system for solving problems for them at a cheaper cost. This system will mark attendance of each employee and calculate the salary of them at the end of month. It also calculates overtime and total working hours of each employee. As in small scale each company has their own holidays preference and variable week off for employees, so all this power is given to the employer to manage holidays and week days of each employee separately.

It saves lots of time and has no error in pay calculation hence preventing clashes between HR Team and employees. So that both employer and employee can focus on their work to develop their company.

Keywords : attendance, employee management, payroll, salary calculation.

\section{INTRODUCTION}

Every organisation keeps a record of their staff. Staff records play a crucial role in staff management. Every organisation requires these records to calculate pay, manage workforce and see performance of employees [1]. Management of all these records is a challenging task and time consuming process for the HR team [3], which can be reduced by using EMS that is the Employee Management System [5]. Human resources are an important part of any organisation and responsible for the success of an organisation. Organisations invest highly on the management of employees. HRIS is a human resource information system that manages inventory control and accounting [6].

EMS is also an informatics system that is useful in saving time, power and money of owner, HR's and manager. All organisations both private and public [5], have necessities of employee management systems. But from years they have been using an old classical method that is pen and paper to maintain record, however in the past few years there has been a large increase toward using automatic systems[11] that can manage salary calculation by their own. In many areas it's a difficult task to implement these systems as they are costly and require proper maintenance. So, to solve this problem I have this EMS, which is mobile application based. It will calculate the salary of each employee and daily attendance. This system was developed such that it can be used by small organisations also. It's cheaper than other systems and helps small scale industries to manage their employees. As in small sectors there are lots of labour as a worker, there are lots of disputes also seen, due to improper calculation of pay and overtime, this system aims to solve this issue, so that the HR team can focus on other processes rather than solving disputes. It helps an 
organization to simplify the process of record maintenance.To make their work more effective, organisations must implement this employee management system [4.]. This paper discusses the development procedure, problems faced and benefits of using the system. This system consists of two mobile applications which one for HR team to manage employees and another for Employee to mark their attendance through QR code.

Two app developed to manage the system are :

1. Employee -

for the Employee to mark attendance personally.

2. Employer -

to manage employees and mark attendance for those not having smart phones.

\section{Background}

To develop this system we need proper analysis of the system. It requires a proper understanding of how the industry works and makes salaries of employees. EMS requires both understanding of backend and frontend, and one must make sure that both of them sync properly. We require proper understanding of databases and designing of databases such that every need of the system can be achieved. There should be a proper GUI available to users to use the app. To build application flutter is used as it provides cross platform development, means the same code can build apps for both ios and android mobile phones. To store data in the database online cloud storage of firebase is used. To make users firebase email authentication is used and to store data firebase firestore is used. Framework used in this development is android studio. The whole system has two types of users one the head of organisation, may be HR head/owner as an admin, another is an employee as a user. However an employee can not register until he/she has been added by the admin in his/her organisation under employees list. It has been specially designed such that most of the control of data is with admin, employees can update on personal details, else everything can be done by admin only. How the data is accessed by users is shown below in figure 2.1, below -

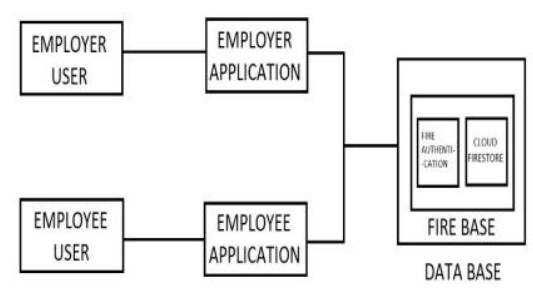

Fig 2.1 System Background Design

III. PROBLEM STATEMENT

Employee management system is a system developed with an aim to solve the problem faced by organisations while calculating salary of each employee. This system aims to maintain proper automatic attendance so that no cheating in attendance can be done by any one. This system makes sure that all the important calculations should be done to calculate salary properly. EMS promotes automatic use and ensures employees that their salary would be calculated properly without any cheating. Proper holidays, week offs and festival holidays granted by organisations are kept for each employee. It provides flexibility of choosing different days off for different employees and accordingly salary would be calculated at the end of month, because of this feature salary may vary according to week days off given to employees if varying week offs.

Develop a system that helps an organisation in handling their employees. The system should provide a facility to maintain attendance and at the end of the month should give the calculated salary, leaves and working hours of their employees. The main task of this application is to record daily attendance and give the calculated salary, present days leaves taken and working hours. At the end of each month the HR team use to invest a lot of time on this task[8], because of which it happens many times employees don't get their salary on time, which results in destroying the employee and employers relation, which directly affects the growth of Company. The challenge to this project is developing a system to make this process smooth, better, reliable and simple.

\section{PROBLEM DISCUSSION}

Management of employees has been a crucial part of any organisation. Proper management of employees is a necessity of each and every organisation. Management of employees is a very broad concept, while here in this paper we would 
be looking at some important areas which affect working of employees. Here, we would be working on making salary calculation and the task of marking attendance easy, time saving and genuine. The main aim of this system is to prevent any kind of cheating and help the HR team to calculate pay correctly. As it is seen many times due to calculation mistakes there are clashes between employee and employer[14], which result in damaging relation and effect overall performance of employee which result in success of organization. So, this system aims to provide smooth and comfortable working of employees so that organization can grow and mark their goals.

Development of this employee management system consists of developing two Android applications. One Android application is for an employer and the other one is for an employee. The main application which will work is an application with an employee. The employer's application is only for registering the employees and providing them access so that they can get registered with the company.

Employer's application -

This application is used by employers in which they will be putting the required credentials of an employee after which employees will be able to get themselves registered with the company and login on their app.

\section{Employees application -}

After getting registered on this app employees will mark their attendance on the basis of which their salary would be calculated at the end of the month.

\section{v. OBJECTIVE}

Objective of the employee management system is developing a simple, cheap and reliable system to achieve the goal of making attendance and salary calculation of employees easy and genuine. We aim to develop a system that prevents cheating by employees and make sure they get each penny of their hard work. This system is developed with the main objective to solve the problem of small scale factories and businesses that are still using pen and paper to maintain staff records. These industries even face many clashes with employees [13] as most of the staff working here is from labour class and they really do hard work to earn, so our system will put an effort to reduce these clashes and will make sure that these workers get each penny of their work.
This system will save a lot of time for the employer and reduce the tension of handling pay for employees. So, they can focus on other things and developing their businesses.

\section{SIGNIFICANCE}

EMS is a very useful and important concept which should be used by every organisation[10.] . In the coming time when nobody will be having time this system will be very useful in managing staff. This system can be extended to various other services such as measuring performance of each employee[9.], deciding whether an employee is underpaid or overpaid, calculating requirement or excess staff etc. However all these topics require more research and time. It will not only benefit organisations but also help employees track his/her performance and improve it[6].

\section{LITERATURE REVIEW}

Literature review consists of various sections that tells us about application and benefits of using this system.

\section{A. Existing System}

The existing employee management system in the organization still uses the ordinary classical methods which are merely based on pen-paper to record the data of their employees[1.][2.]. Large quantities of registers are to be maintained for this purpose which results in downright waste of time in generating reports or searching for employee's records and loss of data if any file is lost. It is also an arduous task for organizations as it is an expensive process. However, somewhere new technologies such as web based systems, Iot based systems are used but they also are costly and difficult to implement at some places.

The other techniques that are in the market are dependent on facial recognition, biometric scan or card punching. But all of these require an external device to be installed in the working area, which is again a costly process and requires regular maintenance[7].

This project eliminates or reduces as much as possible the difficulties of the existing system and avoids errors while entering data. In comparison to the existing system it is cheaper, easy to implement, easy to use, no maintenance required, on time data and saves lots of time.

\section{Disadvantages:}

- Require external device, which is costly and require heavy maintenance

- Needs an extra manual effort. 
- Time consuming process.

- High risk of data got lost.

- Risk of making errors which entering data and calculation

\section{B. Proposed System}

The proposed system is based on an application that runs on smartphones, and requires internet connectivity. This system provides facilities listed below:

1. employer has to add employee and required details,

2. employer can set public holiday of an organisation a day before

3. employer can not edit the holidays that have passed

4. employer have to click get salary to get salary of every employee, he will get a salary of previous month

5. employer can edit and delete the employee

6. the employee has to install the app and follow the described procedure to set up the app, and then he has to scan the QR code for In at a time of entering the premises. And, has to scan another QR for Out at a time of leaving the premises,

7. It provide secure and strict rule for attendance marking as employee can only mark his attendance once in a day

The only requirement to use this system is that one needs to have a smartphone which is not a big task in today's world. One more thing which is kept in mind for those who don't have smartphone that is every employee needs not have a smartphone. There is an option in the employer app through which employers can mark the attendance of his/her employees.

\section{System Architecture :}

The proposed system is a mobile based application having two apps for two types of user a) Employer b) Employee. The data of a system is stored on cloud storage of firebase. Firebase handles security and provides free support for email authentication [2]. It also gives an automatic unique id to each user. It provides various other facilities such as email verification and service to restore passwords. This firebase stores data on cloud[12.] firestore which stores data in the form of collections consisting of documents and fields. The structure of the database is shown below through the ER diagram in figure 7.1 .

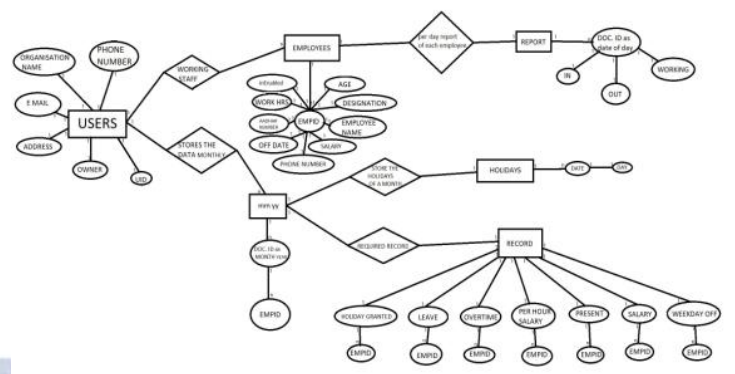

Fig 7.1 ER diagram

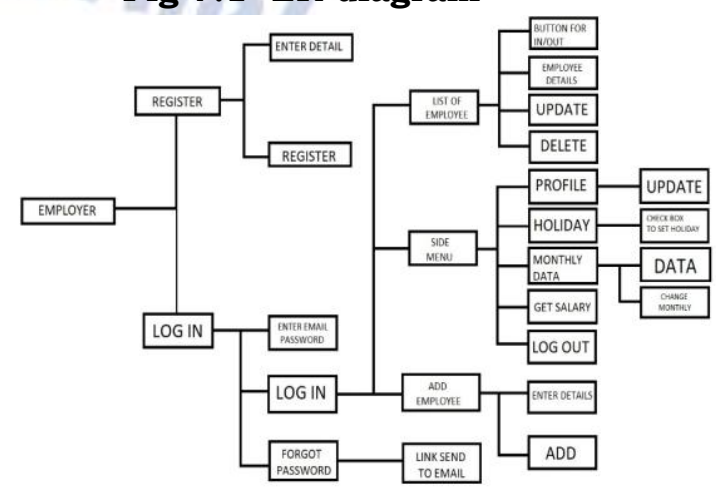

Fig 7.2 Architecture of 1st application (Employer) -

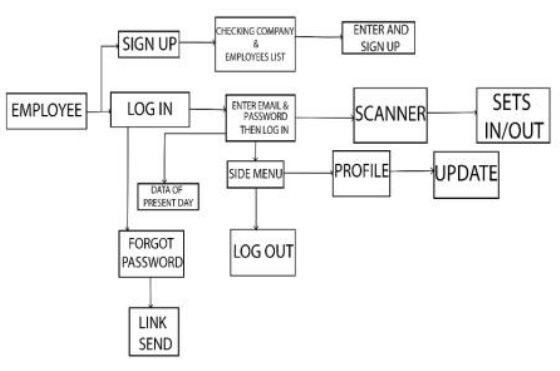

Fig 7.3 Architecture of 2nd application (Employee) -

\section{Features :}

Feature of EMS are as follows:

1. Compatible with both android and ios

2. Easy to use

3. Daily in and out marking, and updating total working hours, present days.

4. Calculation of salary, overtime, leaves at just one click.

5. Reliable and easy to implement

6. Ensures one time attendance marked in a day.

\section{E. Advantages :}

As EMS itself, has lots of advantages and this proposed method of EMS using mobile application based has some extra advantages over other systems such as automatic sensor 
based method or old classical pen and paper method.

1. It is cheaper and easy to use.

2. It gives errorless calculations,

3. Prevent any kind of malpractice by employees,

4. For those employees not having smart phone or don't know how to operate, there is a system provided in the employer app from which any authorised person can mark attendance of all such employees.

5. On time salary calculation in just a click, help strengthen the employer - employee relationship.

6. Flexibility with different off days for each employee.

7. Holidays can be marked a day before by the employer.

8. Shows present and absent employees on the main screen.

9. Provide working hours to employees for each day.

10. Make sure employees can only enter/leave once in a day, this feature prevents cheating by any employee.

\section{CHALLENGES IN IMPLEMENTATION}

Every system had to face lots of barriers before becoming successful.Challenges faced while developing and implementing system are :

1. While developing this system keeping data safe was a challenge, it was a challenge that anyone knowing company should not get registered as an employee, So this was handled by keeping a check whether that company is registered or not and then checking whether that employee is registered or not.This way before registration of employee it's presence is checked.

2. Another challenge was making sure that no employee marked their attendance twice, so for that check is applied whether an employee has entered organisation today or not if not entered then only allowed.

3. Another bigger challenge was managing holidays because in small scale factories and companies it may happen that some staff is called on some day and some on another day, however, their salaries doesn't effect, but my aim was to get exact calculation and manage this system of holidays so for that, another field named as "Days Off" is declared that set the odd days of each employees separately and accordingly calculations are done.

4. Since, labour might not be having smartphones and many of them would not be knowing usage of android system, it was a great task to make a system such that it can be used widely else it not be useful. For that I have given a system in the Employer's app from where attendance of any employee can be marked.

5. It is also difficult for this system to be used properly by companies because any type of mistake can not be solved later, every one using this system has to make a habit of using it and remembering to in and out properly, otherwise it may create a problem for them and finally affect their pay.

\section{IMPORTANCE}

The management of employees is very important for a business to develop. Employees are the backbone of any organisation.[3.] The reason behind necessity of employee management system is as follows :

It allows confidentiality:

- As this saves data in a database which is safe and only the head of the organisation, having access to the Employer app can see data.

- The specific data of employees can be viewed by only the head of the organization or admin of the software. Subsequently, it is more secure to have an employee management system in an association, huge or little, than have financial balance data lying in some cabinet which has a risk of getting lost and even cheated. This can guarantee confidentiality, efficiency, accuracy, availability, updates on time-bound information etc.

- Accuracy of a system is guaranteed, as all the calculations and attendance are marked by an automatic system, there's a rare chance of any mistake. Even to make sure that system runs correctly almost all the test cases are kept in mind while development.

- It provides a ready source of information:

- Between the employee and organization Employee Management System executes as a promptly accessible source of information. The most database systems that consist are work schedule, salary information, posts, Contact information etc. 
- Data updation:

- Employee management systems provide a facility of updating the data. However, professional updates can only be done by organisation and the employee has only permission to update his/her personal details. Provide large efficient system:

The system is highly efficient as it saves a lot of time and reduces mistakes made while managing manually. This in return prevents clashes between HR team and employee and makes sure that organisation focuses on development not on solving clashes.

\section{DEVELOPMENT METHODOLOGY}

Development process used in developing this system is the same as used in web-based applications. Software is developed such that it can be reused and it is impractical to develop the whole system in advance, so it is to be developed in incremental order [15].Incremental development is a approach in which a system is developed as a series of versions (increments), with each version having add on functionality to the previous version.

\section{A. System Analysis :}

Employee management system to be developed such that it is capable of marking attendance of each employee. Data of users should be secured and must be accessed easily whenever required. Data to be structured such that it can be reused. Proper management of holidays to be done, which is an important concern in calculating salary of employees. Applications should be capable of giving salary, total working hours, overtime, present days at the end of month in just a click.

\section{B. Planning :}

This section of development includes proper planning of steps and timeline according to that. It is necessary so that the development process goes smoothly and gets completed on time. It includes planning of the process to execute the project and make it achieve its targets and using such that it does not create any problem in future.

\section{Design Analysis :}

Design analysis is a step in which each design of screen is planned and analysed whether it would be capable of giving desired results. This step is repeated whenever required. If something new or update is required that begins from here. The most challenging part here was to make design such that
It give simple user experience. It is an incremental step in which first designing is done such that it is capable of implementing all the required functionalities and later on design can be made attractive.

\section{GUI construction :}

After getting a clear image of screens and its design, the UI of the app is developed through code. Since this development took over flutter, for designing and implementing backend processes single language is used that make this technology much easier and efficient. The task is to implement it and handle the errors that arise for which we need to search over the internet. This part requires me to read official documents as well as other sources over the internet.

\section{E. Database Design and its Implementation :}

Designing a backend involves designing databases as well as classes according to functionality we want to provide. For databases I have used Cloud Firestore. This was really the most challenging part for me as I have to think again and again that data should be stored such that It can be accessed easily as well should not be mixed, there was a high risk of getting data stored multiple times because that is to be used at multiple places and another task was to store data so that It remain separated, another was to identifying what and where are the fields required.

\section{F. Integrating Database and GUI :}

Now, the most important part came into image , where we require our functions to store and retrieve data. Since data requires updation, we have to keep in mind which data is used how, so that nothing will be lost. One mistake can make your data vanish, however that happens once while developing.

\section{G. Implementation :}

Implementation is a step in which we would be developing our working application. Here, the functionalities and data is implemented and used respectively wherever required. Implementing whole code and checking for error is done here itself. This is the part where most of the development takes place and we get our final product after this step.

\section{H. Testing :}

This is the most frequent step involved, we need to test after completing each task. We also need to 
recheck old functionalities once new ones are developed. We have to make sure the new thing doesn't affect the older one. For testing my application I have runned emulator provided by android studio.

\section{Deploy :}

After getting both applications developed and passing their testing, the system is ready to be implemented in industries. It is now ready to be used by society and further development will be continued lifetime as new technology and ideas arrive.

\section{J. Update and Maintenance :}

Update and maintenance of applications is an incremental lifetime step which will be continued as we encounter bugs and problems.

\section{OBSERVATION AND RESULTS}

After successful development of the system having both the applications working fine, following observations were made :

System works fine and all functionalities are working fine, an employer is able to mark attendance of employees, adding new employees to the list, updation and deletion of employees if required. Employers can mark holidays of whichever day, but here one constraint is put that employees can change holidays of only the same day or coming days, no one can edit holidays of previous days and it is seen that this function is working fine.

Employers can see the list of present employees with their name with blue color under option monthly data and it also shows total working hours till date along with total present days for a month. System is capable of calculating salary at the end of the month, employees can get salary only after the month. If the employee is leaving in between he/she can't be provided a salary on the same day. They will get a salary after the month is completed. Another feature that a person can only mark his attendance once in a day is also working fine.

Another application employee one is also found achieving it's target that can mark attendance by scanning QR code.

However, this system cannot be used to manage any type of advance and can be applied only to day shift (these features are not added currently but can be added easily in future update and development).

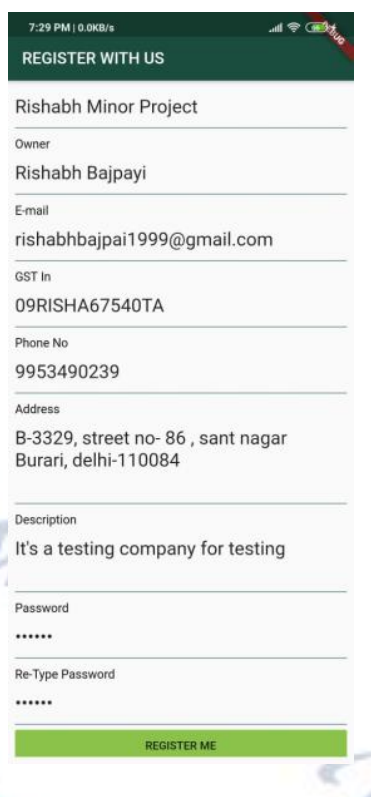

Fig 11.1 Organisation Register screen

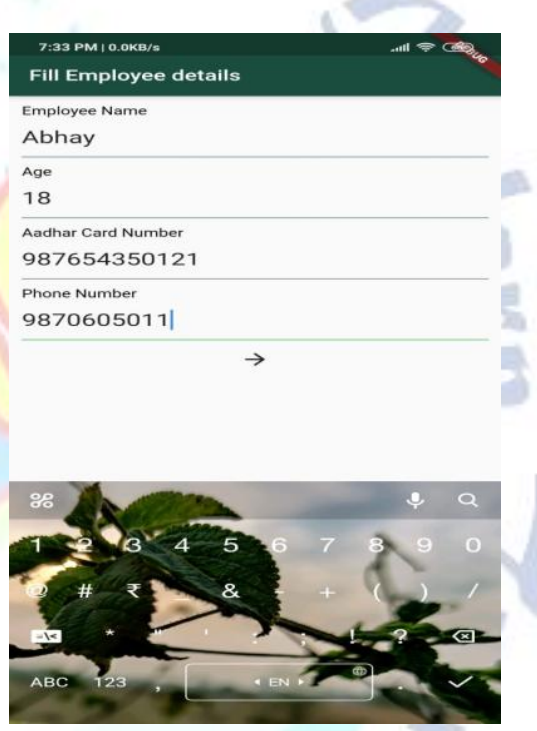

(a)

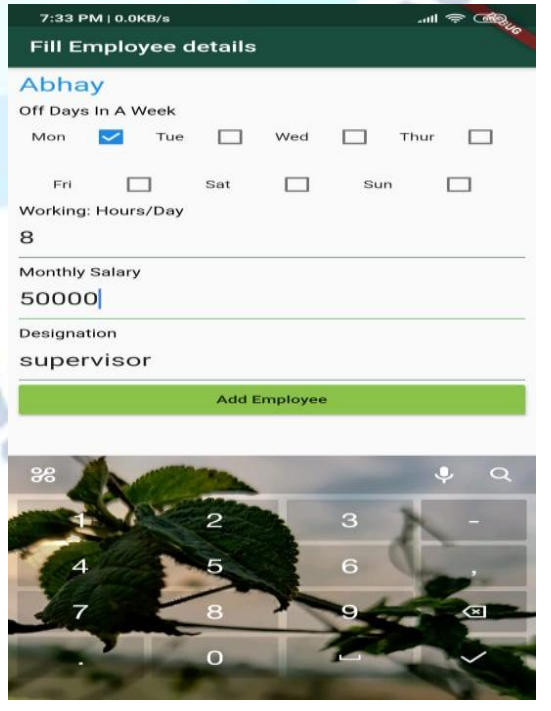

(b)

Fig 11.2 Employee adding Screen 


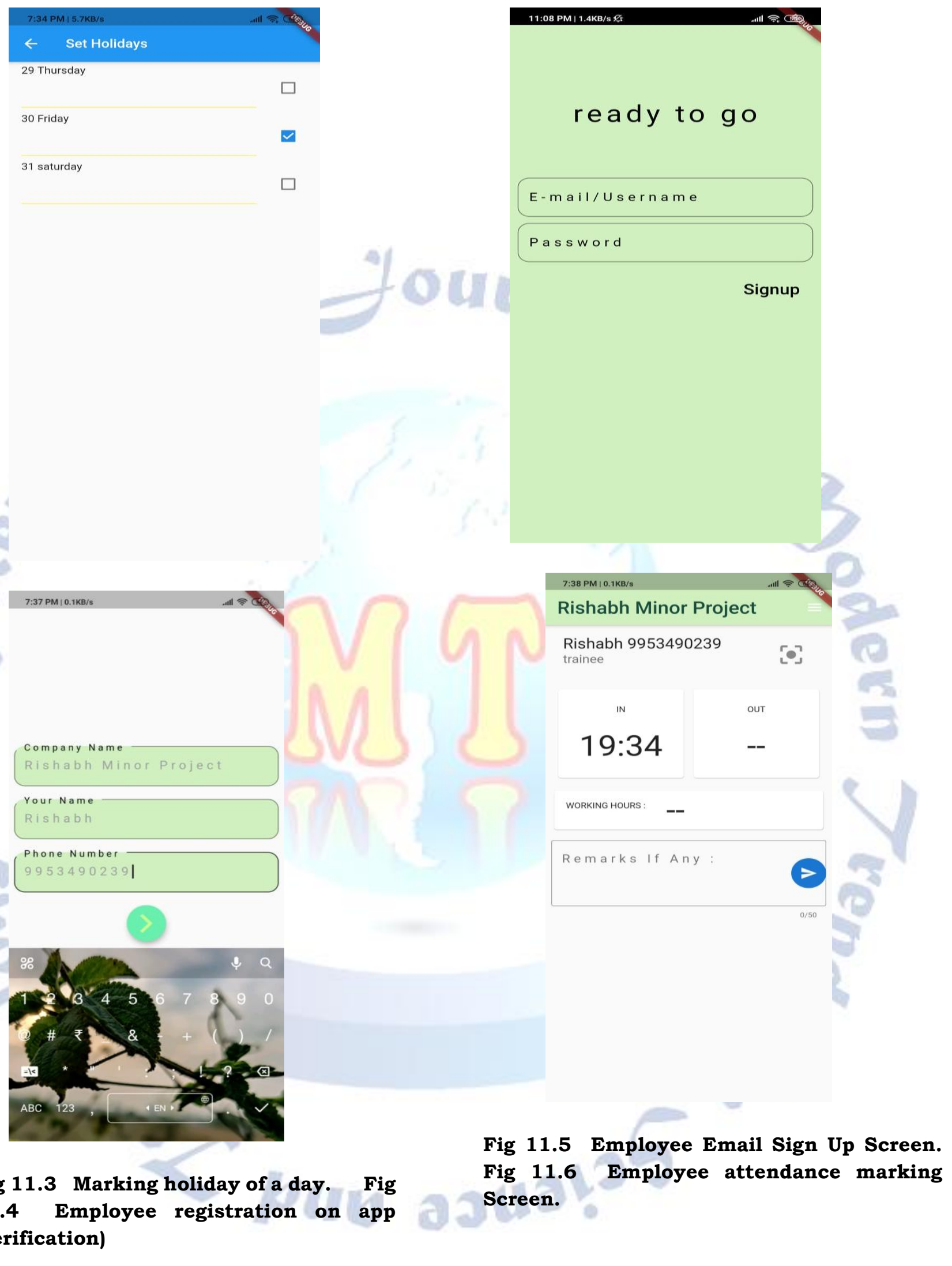




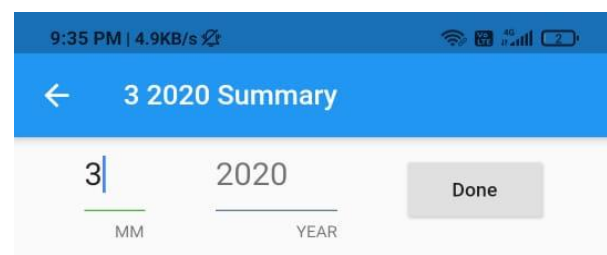

Sorry no data present for given month

\section{Data doesnot exists}

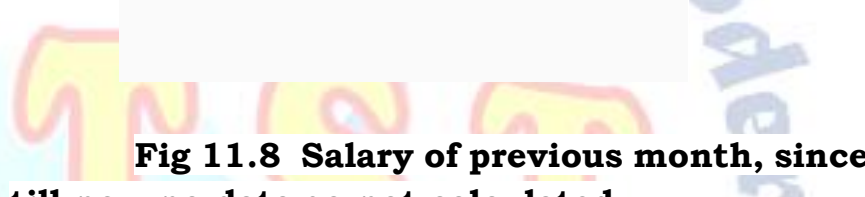
till now no data so not calculated.

\section{CONCLUSION}

This system will help the organisations develop their system and will help in managing employees.The employee management system is designed to save money, time and power. In an organization to simplify the process of record maintenance it is very helpful. As employees are the backbone of any organisation so it is necessary to keep them happy. This concept will bring transparency in their wages calculation. It will also make the HR work easy so they can focus on some other work. This employee management system manages the overall performance and different aspects of an employee in an organization.

\section{REFERENCES}

[1] Engr. Mosud Y. Olumoye, "The Development of computer-based staff management system", EIJST Vol-2, pages 41-51, Nov-13.

[2] Sayali Pramod Dalke, Shruti Anil Deshmukh, Janabai Govind Dalave, Vaishnavi Nitin Sasane, Pooja K Dhule, "Web Based Staff Management System",IJSTE Vol-3, March-2017

[3] Prety Diawati, Vip Paramarta, Djoko Pitoyo, Tomy Fitrio, Sri Wiyati Mahrani, "Challenges of Implementing an Employee Management System for Improving Workplace Management Effectiveness ", Journal of Environmental 
Treatment Techniques, Special Issue on Environment, Management and Economy, Pages: 1200-1203,2019.

[4] Pratik Udayshankar Singh, Hemant Singh Fartyal, Khan Abdul Ahad Zubair, Prof. Akshata Laddha, "Employee Management System ”, IRJET, Vol-06, 5 may 2019.

[5] Sadhana J. Kamatkar, Amarapali Tayade , Amelec Viloria, and Ana Hernández-Chacín, "Application of Classification Technique of Data Mining for Employee Management System", Springer International Publishing AG, part of Springer Nature 2018.

[6] Albert C., Hyde J. and M. Shafritz (1977). Introduction To Tomorrow's System For Managing Human Resources", Public Personnel Management. Academic Journal, Vol. 6 Issue 2, pp.70 - 77 .

[7] Griffin, A. \& Hoyle, M. (2009). Managing Personnel Records in an Electronic Environment. International Records Management Trust, London, UK, pp. 1-2.

[8] Khera, S. N. and Gulati, K. (2012). Human Resources Information System and its Impact on Human Resource Planning: A Perceptual Analysis of Information Technologies Companies. IOSR Journal of Business and Management, 6: 06-13.

[9] A.S.SyedNavaz, A.S.Syed Faiz, C.Prabhadevi, V.Sangeetha, S.Gopalakrishnan, "Human Resource Management System", IOSR Journal of Computer Engineering (IOSR-JCE), Volume 8, Issue 4 (Jan. - Feb. 2013) Page 62-71.

[10] Sahajik Ahmed, Xing Ke, "Human Resource Management, Employees career development impact on organizational performance", ICSSSM, 2016.

[11] Kancho Kanchev, "Employee Management System", ISSN, ISRN, VXU/MSI, Dec-06.

[12] Ashis Data.Md. Rahu Islam, Amit Kumar Mukharjee, Debadatta Kadar, "Cloud Computing: A solution to Human Resource Management System”, Publisher IEEE, Radar, ICRCC 2012 International Conference, Feb-2013.

[13] de Waal, A. A., \& Heijden, B. van der. The Role of Performance Management in Creating and Maintaining a High-Performance Organization. Journal of Organization Design, 2015;4(1).

[14] Schraeder, M., \& Jordan, M. Managing Performance: A practical perspective on employee performance. The Journal for Quality and Participation, 2011:4-10.

[15] Ian Sommerville, "Software Engineering", 9th Edition, Addison-Wesley, 2011

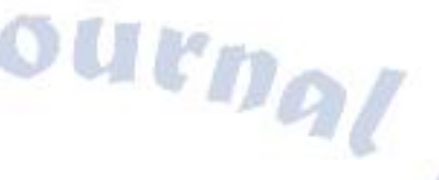

